\title{
UNA CIUDAD EFIMERA \\ Consideraciones sobre las características materiales de Buenos Aires en la segunda mitad del siglo XIX
}

PANCHO LIERNUR *

"...construir ferrocarriles en un país bárbaro, sin los recursos de una cultura esmerada, haciendo mal las cosas pero de rápidos resultados para hacerlas mejor cuando no esté uno de prisa."

Samiento, El camino del Lacio, 1879.

"Y eso da una impresión de cosa provisional, de comercio instalado alli al azar, como acampado..."

Huret, De Buenos Aires al Gran Chaco, 1911.

I.

Contamos con unas pocas representaciones para pensar la ciudad de Buenos Aires, en la segunda mitad del siglo XIX.(1) Una de ellas remite a la "Gran Aldea", la ciudad de casas bajas de patios, blanqueadas a la cal; con sus iglesias, su cabildo, sus quintas, su fuerte, su río. Asociamos la otra a las ilustraciones del Centenario: lujosas mansiones afrancesadas, la Avenida de Mayo, los conventillos, ei Colón, los faroles, el puerto, el empredrado.(2) Menos difundida que las anteriores, para algunos habría existido entre ambas la Buenos Aires italianizante de Mitre y Avellaneda; la ciudad de la aduana de Taylor, del Colón de Pellegrini, del Club del Progreso y los primeros inmigrantes apiñados en las viejas casonas de San Telmo.

Las tres tieneu en común un a mbiente sólido y de cierta coherencia. Sin embargo, sea porque se consideren los trabajos que muestran grandes oscilaciones en los movimientos migraterios; o aquellos que señalan la inestabilidad ocupacional y los continuos desplazamicntos y cambios en la produccion;(3) 0 anás simplemente porque se lo piense desde el sentido común; sorprende que nunca se haya trabajado con una bipótesis menos "definitiva" de la imagen urbana.

Es razonable pensar que durante suvertiginoeo crecimiento Buenos Aires tuviera más aspecto de "Far West" que de chato pueblo colonial o de luminosa metrópolis europea.

\footnotetext{
- CONICET/ lastituto de Arte Americano, Universidad Nacional de Buenos Aires.
} 
Quiero decir que Buenos Aires debió ser en esos años mucho más americana, más modernamente americana y con ello no formalizada y caótica, de lo que estamos babituados a imaginar.

Sin negar la formación paralela de la "metrópolis moderna", sólida, del Centenario, el objeto de este trabajo es revelar el estrato efímero subyacente a esa "metrópolis", estrato que configuró en su momento una considerable porción del artefacto urbano aunque no dejó las huellas en el papel de los proyectos, ni en los muros adomados que hoy nos impresionan. Quizás por eso no la vimos.(4) O quizás porque hasta hace pocos años estuvimos instalados en el Centro, muy cerca del Poder y de la Plaza, y desde allí hemos mirado sólo unos monumentos siempre sólidos. Cuando nos desplazamos a la periferia en cambio, las formas pierden sus perfiles nítidos, el orden se distiende y comienzan a advertirse los vacíos, los flecos, las flojedades.

Pero también debió ser nuestra forma de seleccionar y leer los documentos la que fue volviéndola invisible. La "ciudad efímera" se registra en los censos, como comprobaremos en seguida, pero esta es una huella demasiado tenue, no decisiva para este objeto: con frecuencia las construcciones son tan transitorias o tan clandestinas que no pueden o no quieren ser registradas oficialmente.

En las fotografias y los daguerrotipos en cambio, el espectro se reconoce, con las mismas formas borrosas y leja nas de la escena clave de "Blow up". Hemos aceptado con su enunciado central de logros (la casa, el tea ro, el monumento, el parque) a las imágenes que aquellos fotógrafos lanzaron hacia el futuro como los testimonios del Progreso. Sin embargo, basta mirar sus rasgos secundarios, transformar el fondo en figura, para advertir allí donde la voluntad de representación se descuida, la elocuencia de esas buellas de la fugacidad.

II.

Examinemos una fotografía muy conocida. Se trata de la que lleva el número 196 del Album de vistas, tipos y costumbres del Buenos Aires Antiguo de la casa Witcomb.(5) Su protagonista es el borde sobre el río en la zona central de la ciudad. El plano está dividido en forma horizontal; la mitad superior es blanca y corresponde al cielo, la inferior, oscura, está ocupada por el río. En la angosta franja con edificios que atraviesa de lado a lado el centro de la imagen, al menos un quinto corresponde a una obra de gran importancia institucional y arquitectónica: la citada Aduana de Taylor. La Estación Central llena algo más de otro quinto de la franja. Aduana y Estación son los emblemas del Progreso, los restos del Fuerte de la Gran Aldea.

Pero, qué otras cosas podemos ver recorriendo de Norte a Sur con una lupa el paisaje que sirve de "fondo" a esas figuras principales? Comenzamos con una casa de dos plantas, seguramente sobre Paseo de Julio, debajo de la cual unos arcos ocupan un plano algo más avanzado. En la misma dirección éstos prosiguen por debajo de un edificio identificado como "café/restaurante", quizás de madera. Detrás, por encima de este 
último y sobre alguna terraza se distingue una construcción indudablemente de lata con un cartel que anuncia tna "Hojalatería". Siguendo hacia el sur bay una casilla prefabricada del ferrocarril en el mismo nivel y el mis mo pla no que los arcos, por delante de unas pocas casas bajas, y más al oeste del "Hotel del faro". Vienen luego tres edificios bajos de albañilería, y el "Hotel del Globo", que se recorta sobre la silueta de la cúpula de la catedral. Pegado a ellos hay un grupo de construcciones precarias, probablemente casillas y depósitos, a los que siguen varios edificios de poca altura, uno de ellos con torreón, y detrás el Teatro Colón. Desde las construcciones precarias bacia la izquierda, ocupa un buen tramo el primer plano de la Estación Central, prefabricada en chapa y madera. Sobre las vías, entre la Estación y la costa se ven varios vagones y otra casilla prefabricada de madera. Inician en seguida las formas del Correo con fondo de las de la Casa Rosada, a las que sigue la Aduana Nueva. La última construcción sobre la izquierda es el muelle de madera.

Podríamos completar la observación con dos operaciones. Una consiste en imaginar lo que el hemíciclo de la Aduana Nueva oculta (foto 197 del Album): el barracón de la Estación Venezuela y las casuchas que la rodean, el precario viaducto de San Telmo y más a trás el corralón de maderas de Tomas Dreysdale. Otra es continuar nuestro giro hasta los 360 grados para comprobar que como observadores estamos instalados en el extremo del muelle de pasajeros, una importante construcción de madera que desaparecerá pocos años después.

Qué nos dicen acerca de esta "ciudad efimera" los grandes relatos sobre Buenos Aires? No la registran, pero tampoco la niegan.

Si se obscrvan las imágenes que acompañan a esos trabajos, la "ciudad efímera" suele estar muchas veces frente a nuestros ojos. Cuando leemos los textos no se le reconoce una entidad sustantiva, y si esto ocurre se trata de una presencia furtiva. Scobie, por ejemplo, la ba insinuado apenas.(6)

Quizás porque la materialidad del artefacto urbano no está en el centro de su interés, - porque procura marcar la separación entre la ciudad del Centenario y la ciudad de Caseros, su trabajo saltea la ciudad del campamento. Se refiere en detalle al barrio en torno a las Plazas de Mayo y Victoria, apoyado sobre todo en el censo de 1869, pero no alude a las características constructivas de los conventillos. Cuando describe un "paseo por la ciudad" pasa de la Plaza Constitución, por la calle Lima, hasta la calle Victoria diciendo: "después de un viaje de diez cuadras se llegaba a Plaza Monserrat. La ruta atravesaba dos parroquias, la de Concepción y la de Monserrat (...). Aquí las casas y calles parecian más nuevas que al sur de Plaza de Mayo. La edificación más característica era la modesta casa de una planta construida alrededor de uno o dos patios interiores ocupada por una sola familia. Frecuentemente, sin embargo, varias familias compartían una casa grande, de uno o dos pisos, dividida en departamentos de doso tres habitaciones que daba a corredores o patios". Luego de describir las características sociales del barrio, Scobie prosigue con un salto brusco: "Desde la Plaza de Monserrat, (escribe) una breve caminata por la calle Lima desembocaba en la calle Victoria". 
Nada de lo dicho es erróneo. Sin embargo, si en ese imaginario paseo en algún momento de la década del setenta, alguien hubiera llamado la atención del gran historiador norteamericano acerca de las particulares características materiales de muchas de las construcciones frente a las cuales pasaba, y si además se hubiera tenido en cuenta que por Reglamento del municipio las fachadas de los edificios de madera y chapa debían ser construidas en albañilería, podría haberse formulado una representación algo diversa de la ciudad, indicio a su vez para otras lecturas de su historia.

Veamos. Toda la manzana al oeste de la Plaza Constitución, la bordeada por Santiago del Estero, Pavón, Salta y la actual Constitución, estaba formada por barracas y casillas precarias; y de los dos terrenos en que estaba dividido el frente de la calle Constitución sobre la misma plaza, uno era un baldío y el otro estaba apenas ocupado también por construcciones de madera. Caminando por Lima hacia Victoria, en la esquina noroeste del cruce con Cochabamba había tres construcciones del tipo que estamos describiendo: dos conventillos, parcialmente de madera, de 12 babitaciones cada uno; y una mezcla de enorme barracón con cuatro babitaciones, totalmente de madera. En la manzana siguiente, casi llegando a Comercio, sobre la mano izquierda, se levantaba otra construcción de madera, y en la esquina esta ba el gran galpón de chapa donde Luis Martínez Otamendi tenía un "molino de aserrar". Entre Comercio y Europa sólo se veían construcciones de albañilería, pero llegando a Estados Unidos se volvía a encontrar otro gran conventillo de madera y en la esquina un baldío, como lo era todo el terreno que se extendía sobre el frente de la calle hasta Independencia. Pasando el Mercado remataba la cuadra siguiente un conventillo de madera de 10 habitaciones. Seguían, entre Salta y Méjico, casi llegando a esta última, dos conventillos precarios, uno de 18 habitaciones, y otro sobre Méjico, en la vereda de enfrente, parcialmente completado del mismo modo en los fondos; había también una caballeriza, en parte de madera, tres predios más adelante. En la próxima cuadra continuando hacia el Norte se encontraba sobre Independencia una barraca con 20 habitaciones. Muchas de las casas de Belgrano y Moreno tenían agregados precarios y acumulaban más de cuarenta habitaciones. Llegados así a la Plaza de Monserrat se hubiera advertido que había frente a ella, entre uno de sus bordes y la calle Lima, dos terrenos ocupados casi totalmente por construcciones de madera y chapa, uno de los cuales, de casi un cuarto de manzana era un conventillo de 24 habitaciones "con barraca". Ahí nomás, en Santiago del Estero y Salta, podía verse un conventillo "de chapa", con 32 habitaciones propiedad de los Lanús. Siguiendo por Lima, había también un galpón de chapa en medio de la manzana; y enfrente, ocupando casi media cuadra, un enorme patio bordeado de tinglados de madera que albergaban 18 habitaciones. Otro galpón de chapa cubría el segundo terreno pasando Victoria, y podía culminarse la caminata visitando sobre Victoria o sobre Rivadavia cualquiera de los conventillos precarios que había en cada una.

Descartando los "pueblos" periféricos, y las zonas bajas e inundables, y teniendo en cuenta como hemos dicho que cierto tipo de construcciones no debieron siquiera ser registradas, puede pensarse que las condiciones eran similares en otras zonas de la 
ciudad.

En el norte, por ejemplo, en el sector limitado por Juncal, Callao, Córdoba y Uruguay la relación entre construcciones precarias y de albañilería se daba del siguiente modo, diferenciándola por precintos: Juncal, Uruguay, Arenales, Libertad: 11/57; Santa Fe, Montevideo, Juncal, Uruguay: 13/32; Córdoba, Montevideo, Santa Fe, Uruguay: 52/ 173; Córdoba, Montevideo, Santa Fe, Callao: 42/102; Arenales, Montevideo, Callao, Juncal: $16 / 40$.

En el sur, en San Telmo, la incidencia era menor, pero igualmente relevante: $15 / 46$ en la manzana de Garay, Perú, Caseros y Chacabuco, por ejemplo.

III.

Es cierto que toda ciudad moderna es efimera, puesto que su renovación constante es una condición de su existencia. Pero en este caso esa característica puede entenderse como un rasgo particular (común a otras ciudades argentinas y americanas de este período).(7) Es que lo efímero, lo transitorio de las construciones porteñas entre Caseros y el '90 parecen expresar no sólo la pobreza de algunos sino una incertidumbre generalizada, el estadio anterior al de un proyecto consolidado, un tiempo sin utopia compartida. Moderno por añadidura, puesto que ¿no era precisamente "sacblich", puramente objetivo, "amerikanismus" absoluto este galponerio ingenieril que se quitaba impudorosamente todos los ropajes de la "Cultura" del mismo modo en que lo estaban haciendo al mismo tiempo y para escándalo de "Europa" los americanos del otro hemisferio?

El tiempo de lo efimero es el de una suerte de presente absoluto: apto para despegarse del pasado cuando no interesaba sujetarse a las formas, a los proyectos y al futuro. Estas construcciones expresan distintas formas de manifestarse de esas afirmaciones de puro presente: las que se jugaban todo a una racha momentánea; las que se sabían en una estación de paso; las que no tenían recursos para prever nada.

Claro que Buenos Aires entre el sesenta y el novecientos no era una "ciudad campamento": porque no se trataba de un asentamiento factoria, pero también porque tenía muchos otros elementos, como sede histórica del poder o porintegrar un proyecto más complejo. A pesar de eso, muchos de sus rasgos se corresponden con el carácter de campamento provisional.

Ya a fines de la década del sesenta la ciudad da la impresión de estar siendo desbordada porsu propio crecimiento, delatando la insuficiencia de infraestructura que dará lugar a la epidemia del "71. Si llueve las calles son un barrial; si no llueve son irrespirables. En el verano de aquel año el cronista cuenta: "ayer a las seis y media de la tarde la ciudad quedó envuelta en una tormenta de arena y polvo, oscureciéndose totalmente la luz del día".(8) Y se queja inversamente con la llegada del otoño: "Pobre Buenos Aires!!! No basta el terrible azote de la epidemia! (...) Las fuertes y cantinuas lluvias han inundado por tercera vez las casas inmediatas a los desagües". 
Dieciséis años después de Caseros, William Hadfield (9) señala que "las regulaciones municipales de la ciudad son muy deficientes", preocupado por la falta de instalaciones cloacales. Y veinte años más tarde, otro viajero (10) ta mbién considera que "BuenosAires será seguramente una ciudad estupenda; pero faltan todavía ocho o diez años antes de que esto ocurra y mientras tanto la ciudad actual es como un esbozo transitorio, sin atractivo, incompleta".

Además de hacerlo con el espacio público, la precariedad caracteriza también a las distintas construcciones urbanas. Nos referiremos en particular a las destinadas a vivienda, instalaciones productivas y transportes. No abordaremos aquí por razones de espacio, otras funciones como los edificios para el tiempo libre, las escuelas y las insta laciones para la salud. Todas tienen en común el albergarse en estos tiempos en unos contenedores multiuso, galpones y barracas "sin cualidad", en un estadio previo a las formas especializadas y estables que asumirán en las décadas siguientes. También deben considerarse aparte los monumentos y las casas de la élite.

IV.

Aparentemente las primeras propuestas de viviendas "transitorias" para sectores carenciados -villas de emergencia?- consideradas por alguna institución, en este caso estatal, tienen lugar con motivo de la epidemia de fiebre amarilla.

Uno de los proyectos presentados a la Municipalidad,(11) el del ingeniero Alfredo Abelo, consideraba una alternativa enteramente en madera. En él se ubicaban 12 "casas para obreros" para 4 familias cada una, rodeadas de jardines con árboles "contra las measmas". Empeñado en conseguir bajos costos y un "buen interés" de la operación, Abelo comparaba formas distintas de construir, en planta baja o alta, de madera o mixta, resultándole más económicas por unidad las construcciones altas. En cuanto a los materia les opta ba por el ladrillo: "Se tendrá también casas más durables(decía), sujetas a menos reparaciones, y la economía de las mismas reparaciones compensa el aumento del gasto primero".

Pero su proyecto no se construyó, porque al Municipio no le interesaba la "durabilidad" sino la velocidad de las respuestas: en tres días estuvieron "completamente listas 12 habitaciones" de madera construidas en San Vicente para evacuados de la Capital.(12)Una comisión creada especialmente proveyó enseguida "algunas casas de madera, y pronto (quedaron) concluidas dieciséis de cuatro habitaciones cada una". Generalizando esta solución precaria, el Ministro de Gobiemo ordenó que se construyeran al menos otros cuarenta de estos barracones.

Las "construcciones transitorias" en madera se emplearon también en oportunidad de la epidemia de cólera de 1886. En este caso el Ministro Eduardo Wilde resolvió la urgente contratación de construcciones transitorias para las personas "que sea necesario expulsar de los conventillos por razones de salud pública".(13) Y finalmente se llevó a cabo la oferta presentada por la empresa Sackman y Ocampo.(14) En ocho días se 
montaron 40 casillas de $10 \times 20 \mathrm{mts}$, divididas en piezas de $5 \times 4 \mathrm{mts}$. cada una, con techos de chapas, paredes de pino y pisos de madera. El conjunto, que contó también con una casilla para enfermería, de $8 \times 20 \mathrm{mts}$. con cuatro piezas y un salón, estaba en condiciones de albergar a unas 1200 personas, a razón de 30 por casilla, con un promedio de 3,7 por cuarto.

En enero del año siguiente se inició otra gran construcción de este tipo para los sectores populares: el "Hotel Provisorio para el Asilo de Inmigrantes",(15)un enorme galpón dodecagonal de chapa y madera.

La especulación privada aprovechó las ventajas que brindaban las construcciones en madera y chapa para albergar a los inmigrantes hasta avanzada la década del ochenta, pese a que estas instalaciones precarias comenzaron a reglamentarse desde junio de 1871. La ciudad debió proporcionar cobijo a más de cien mil habitantes nuevos en poco más de cinco años, duplicando su número de habitantes (76.000 en 1852; 177.787 en 1869).

Las viejas mansiones se ampliaron subdividiendo las babitaciones más grandes con tabiques, y agregando nuevas en los lugares libres de los fondos, Ios patios o la planta aita. Estos cuartos de madera y lata sobre las terrazas son los que vemos en las viejas fotografias aun en el radio de la Plaza de Mayo y en muchas otras partes del casco viejo.(16)

El Reglamento de 1871 aprobado por el Senado y la Cámara de Representantes establecía condiciones dimensionales y condicionaba el material de pisos y muros portantes. Prohibía "el uso de tablas viejas en las piezas destinadas a ser habitadas en las nuevas construcciones", pero no impedía su construcción precaria, ni eliminaba las anteriormente edificadas con esas características.

Según otros documentos, la ordenanza fue decretada "en virud de los abusos que cometian arrendatarios de los corralones viejos para establecer conventillos, edificando a la calle altos, con tirantillos y tablas de pino".(17) Todavía en 1889, según Santiago Estrada, el "empresario de viviendas para pobres (...) construye las habitaciones de madera en la generalidad de los casos, de ladrillo y barro en las excepciones".(18)

Si bien las actas municipales registran con frecuencia la construcción de sucuchos, éstos debieron ser generalmente clandestinos. Los inspectores denunciaban el 16 de agosto de 1887 su incapacidad de controlar el proceso pese a habérselo intentado limitar mediante una reglamentación: "en muchos puntos de la Ciudad se continúan construyendo casillas de madera, la mayor parte de ellas en el interior de las casas sin que nos sea posible el poderlo evitar por el cuimulo de trabajo que pesa sobre nosotros y la extensión considerable que tenemos que recorrer".(19)

Pese a la ordenanza del 21 de junio del ' 86 , muchos propietarios intentaron levantar nuevas construcciones, las que fueron denunciadas a su vez por otros vecinos.(20)

Cuando Huret describe los conventillos se refiere también a "esas casuchas (cuyo) piso superior se compone de una galería de madera a cuyo alrededor se ve una serie de habitaciones".(21) Y unas condiciones similares dejan entrever relatos como En la 
sangre, donde Cambaceres describe el ambiente en que nace Genaro, el personaje central de la novela. En El conventillo Luis Pascarella describió así a un constructor: "en la vecindad de Palermo poseía un corralón atestado de puertas viejas, ventanas retorcidas, pilas de tachos, baldosas, maderamen y cuanto trasto aparentemente inútil pescaba en los incendios o demoliciones de edificios. Sin embargo, el conocía sus virtudes; ese montón de cosas viejas y mal olientes, como el purrit resurexit de los escolásticos, contenía el germen del futuro organismo ciudadano. Sus repetidos triunfos habianle infundido el orgullo del vencedor, y (...) sus maderas y tachos, transformados en parodias de casas avanzaban hacia la Pampa desierta (...)".(22)

Los restantes modos precarios del babitar de los sectores populares podrían caracterizarse según diferentes grados de precariedad como: nomadismo urbano, cuevas, casillas improvisadas, ranchos de paja y adobe, casillas industrializadas.

Consideramos "nómades urbanos", los verdaderos vagabundos, a aquellos sin residencia fija de ningún tipo. Las ilustraciones de los magazines los muestran durante el día usa ndo la ciudad como espacio de trabajo o de ocio. La noche los obligaba a buscar algún refugio donde descansar, y en invierno no morir de frío. Para las Señoras de San Vicente de Paul "es doloroso y tan infinitamente triste como un campo de batalla (la batalla de la vida) después de la embriaguez épica del combate, el cuadro que ofrece esta gran ciudad en las primeras horas de la madrugada. Sosegada la bahahola de la salida de los teatros, es de ver ese hacinamiento de cuerpos rendidos por el sueño, tirados por los huecos de las puertas, en los atrios de los templos, y en los pórticos de los edificios públicos".(23)

A principios de los '90, Child observaba que "el Paseo de Julio, aunque muy bien trazado, está completamente abandonado a esas lacras sociales que los argentinos llaman 'atorrantes', extranjeros a los que les faltó el toque de la dama Forkuna yque de caída en caída han llegado a ese punto en el que se aprende a vivir sin dinero, sin domicilio y casi sin ropas".(24)

Según Fray Mocho a estos albergues había que agregar una suerte de boteles de paso, que brindaban un sitio para pasar la noche por unas pocas monedas. Uno de ellos era el Café de Cassoulet en Viamonte (antes Temple) y Suipacha: "Tarde en la noche, cusando el café se cerraba, decenas de desgraciados sin hogar (...) por dos pesos de los antiguos encontraban un techo y una tabla para dormir, y por uno, lo primero y el duro suelo de los patios y pasillos".(25) Las Memorias... también describen durante la década del noventa otros tugurios (26) que a lojan "según el dinero con que cuentan a los desgraciados que vagan sin hogar o a aquellos que legalmente no pueden habitar en parte alguna".

Podemos llamar "cuevas urbanas" a aquellos cobijos encontrados o adaptados para obtener algún reparo, que se ocupaban por un período relativamente prolongado. Los "caños" eran una de sus modalidades: Gutiérrez y González se han referido a una parte de los vagabundos que "solian pernoctar en un depósito costero, dentro de tubos destinados a derivar las aguas al rio".(27) 
Pero encontramos otros e inesperados tipos de "cuevas". Algunas aprovechaban la moldeabilidad de la barranca del río,(28) cuya costa era un habitat vital para los más pobres. Un "atorrante" de Fray Mocho recuerda que "siempre se hallaba entre la resaca un sábalo asonsao, una boga con la jeta rota o un bagre atorao con el anzuelo. Yaura? (se pregunta) vaya uno a dar con el río! ... lo han ido reculando, reculando... hasta el diablo!!".(29)

En otros casos se transformaba en refugio precario cualquier espacio mínimo que nadie reclamara, como lo bace el "ermitaño del ombú",(30) habitando en los buecos de un árbol; o "Carlín Carlucho", dentro de una caja en la barranca de Retiro,(31) o el "atorrante de Palermo", que vivía en una especie de iglú armado con desechos. Las "cuevas" parecen haber sido el refugio de los que buscaban un aislamiento total del resto de la sociedad, descartando incluso las "bandas" que el nomadismo permitía y estimulaba.

Las "casillas improvisadas" debieron constituir el abrigo de los que vivían en las cercanías o en los mismos basurales, buscando entre los desperdicios elementos para vender o aprovechar de diversas formas. A diferencia de la soledad de las "cuevas" o las "bandas" del nomadismo, en las casillas se advierte la existencia de familias. Huret describe el "Barrio de las Ranas" en la quema de basuras: "No se ven alli más que casas construidas con hojalata, cuyas paredes, tejados, puertas y columnas resplandecen al sol. El trust del Standard Oil, (...) ha proporcionado casi todos los materiales. (...) Cortando la hojalata y clavándola de cierta manera, han festoneado revestimientos y ornamentaciones para los arcos de allambras moras, cortado a fuerza de cizalla, columnas y frontones para palacios greco-romanos y recortando en encajes y blondas, las cajas de azúcar de Tucumán, para rosetones de capillas góticas!l...".(32)

Los "ranchos" abundaban en la ciudad a comienzos del período a nalizado. Tanto en el catastro de Beare como en el Departamento Topográfico de la Provincia es difícil distinguirlos de las construcciones precarias de madera. En realidad, la designación es lo suficientemente genérica como para admitir como tales desde una construcción en ruinas hasta una de las que aquí lla mamos "casillas improvisadas". En otras regiones del país,(33) los ranchos se asocian a la construcción en adobe pero esto no ocurre necesariamente en las orillas del Río de la Plata, donde con el mismo fin puede usarse eaña, paja, ramas y, de mediar una cierta cercanía de un centro urbano, los residuos del mismo. El tema ha sido escasamente estudiado para el caso de la ciudad de Buenos Aires, a lo que se agrega una muy escasa documentación y la paulatina desaparición del tipo como fórmula vernácula frente al avance de la modernización.

Las casillas "industrializadas" constituyeron en cambio la modalidad de habitación precaria más difundida e importante. La denominación obedece a que empleaban en su construcción materiales producidos por la industria, con éste u otros fines. Nornalmente estos materiales debían ser adquiridos en el circuito comercial, de modo que la propiedad de estas viviendas suponía una cierta capacidad de aborro. Su condición "precaria" se liga a varios factores.

El primero es el costo relativamente reducido de la construcción más elemental, vale 
decir aquella con los requerimientos más bajos de confort: un único ambiente babitable capaz de proteger al menos del agua y los ladrones a personas y enseres, diafragma entre el espacio público y el mundo íntimo. El segundo es la rapidez del armado: una construcción en seco de este tipo podía realizarse en pocas horas, mientras las construcciones húmedas requerían varios días de secado. El tercero es la movilidad posible en razón de las características desnontables del sistema constructivo y de su bajo peso relativo, y se vincula al costo de los terrenos y a las oscilaciones en las fuentes de trabajo.

Probablemente el primer y más importante asentamiento de este tipo de viviendas fue el barrio de La Boca.(34)

Es sabido que su existencia se liga a la de los astilleros de la Vuelta de Rocha desde los primeros años del siglo XIX. Según Guevara, "las primeras (viviendas) de que se habla en escritos de la época con cierta precisión son de 1848 , de madera, sobre pilotes y con escaleras externas (British Packett; relato de visita de Manuelita). Hacia 1862 los grabados las muestran construidas integramente de madera (Dulin)".(35) Es a partir del ' 80 cuando debió comenzar a emplearse también la chapa, lo que se registra recién en el censo de 1896.

En general las casillas de este tipo se construían en terrenos bajos, los que por ser inundables y carecer de todo tipo de servicios eran los más baratos. Estas zonas abundaban en la geografia de Buenos Aires y coincidian, hasta la electrificación, avanzado el siglo XX, con la localización de las industrias, las que requerían importantes volúmenes de agua como fuente de energía, y empleaban los cauces como redes de transporte. El Maldonado, el Riachuelo, toda la costa del Río de la Plata, pero también los numerosos arroyos que atraviesan la actual región metropolitana ofrecían este tipo de terrenos.

Estas casillas se construían enterrando cuatro postes de quebracho, dejándolos de una altura suficiente como para evitar inundaciones, a la espera de ir rellenando el terreno poco a poco con tierra o con desechos.(36)Sobre éstos se apoyaban las gruesas vigas sobre las que se montarían los tablones del piso. Los parantes de ángulo de los muros externos se abulonaban a los postes; pudiendo armarse el entramado de madera de pino que sostendría las chapas del paramento externo mientras dos de los pla nos que definirían el cubo se encontraban aún en posición horizontal. Tirando luego de los extremos podían levantarse ambos muros, trabándose momentáneamente para fabricar los dos restantes. El techo se armaba luego, una vez fijados los cuatro lados verticales.

Este sistema sencillo permitía albergar a la unidad doméstica mudando rápidamente en un fin de semana los pocos enseres desde el cuarto del conventillo, agregando luego otros cuartos y terminando los paramentos interiores con un revestimiento de madera que mejorara la aislación térmica. Como dijimos, el sistema permitía también su traslado, tanto en el caso de localizarse abusivamente como cuando se asentaban en terrenos a lquilados. Estos movimientos se producían por motivos diversos, pero más frecuentemente obedeciendo a la ya mencionada variación en la demanda de mano de obra. 
Para obtener precisiones mayores hemos estudiado un pequeño sector con las características ya señaladas, en las cercanías del Riachuelo, en las vecindades de lo que fue el "Barrio de las Ranas". El área está limitada al norte por el Parque de los Patricios, al oeste por la Av. Sáenz, al este por los terrenos que pertenecieron a la Compañía Primitiva de Gas, y al sur por las vías del Ferrocarril Provincial. Aunque poseemos datos sólo a partir de 1917 es posible comprobar la existencia de un estrato "precario", anterior a la consolidación de las viviendas de material en la década del 20.

Las casillas se implantan en predios legalmente adquiridos o invadiendo tierras fiscales o privadas. En el primer caso se construían de madera y contaban con dos habitaciones de $4 \mathrm{~m} \times 4 \mathrm{~m}$ o $3 \mathrm{~m} \times 5 \mathrm{~m}$ con galería exterior y un retrete de albañilería en los fondos. Se las separaba de la medianera dejando un espacio posiblemente para el cerco o muro que vendría después, en previsión contra la propagación de incendios en el predio vecino; o bien para conservar su movilidad.(37)

Con el tiempo, en algunos casos la casilla se elimina para proceder a construir la nueva vivienda "de material". Lo más frecuente es que ésta se integre a la edificación posterior, la que se realiza hacia el frente.(38)

En 1904 Cristóbal Sur registraba el más alto porcentaje de viviendas de "fierro y zinc" de la ciudad, y uno de los mayores de construcciones en materiales precarios.(39) Por el plano topográfico de 1904 puede inferirse que la mayor parte de estas construcciones se localizaban en el sector bajo que nos ocupa. También confirma el Censo que los mayores porcentajes de casillas de estos materiales estaban situadas en las circunscripciones más inundables $(1,2,3,4,15,16$ y 17$)$. La Boca tenía 1242 de madera y 1 de chapa sobre un total de 3241 ; San Cristóbal 540 de madera y 100 de chapa sobre 3736.

Aun suponiendo que no todas las casillas se localizaran en los terrenos bajos que nosotros estudiamos, en el Plano topográfico no se registra un número tan considerable de unidades como las que registra el Censo. De manera que podemos inferir que al menos un sector de la zona que estudiamos constituía una suerte de "tierra de nadie" ocupada por este tipo de construcciones precarias.(40)

También los planos de OSN, aunque posteriores, dan cuenta de "casas existentes" de madera.

En cuanto a la movilidad, distintas fuentes documentales completan la tradición oral: ilustraciones en los magazines, solicitudes de transporte, relatos litera rios.(41)

Los desplazamientos eran a veces impuestos por el Municipio con el objetivo de regularizar la traza de la ciudad.(42)En algunos casos esto ocurría por iniciativa de otros vecinos,(43) en otras ocasiones, la administración actuaba por su iniciativa, aunque no siempre con absoluta certidu mbre. Pero lo que parece haber sido más común es que por distintos motivos solicitara el traslado el propio interesado.(44)

Hemos dicho que, al menos en el área que estudiamos, la implantación de estas casillas en lotes está, en muchos casos, regularmente registrada, pero esta legitimidad no se contradice con la movilidad, habida cuenta de que nuchos de los lotes no se 
adquirian en propiedad sino en alquilez.

De todos modos es más probable que la movilidad caracterizara la segunda forma de localización de las casillas, por invasión de terrenos fiscales o privadus.

Y.

Jorge Sábato ba proporcionado una interpretación del comportamiento de la clase dominante argentina en relación con la industria que se correspolio con la notable precariedad que se detecta en los ámbitos de la producción. Para Sabato "a diferencia de otros paises, en los que el sector industrial habia constindo la actividad economica lider (...) del desarrollo capitalista, en Argentina es el sector agropecuario no solo el que impulsa la transformación sino, además el que la domina", por lo cual "toda la economía se encontrará sometida a convingencias y riesgo: comparativamente mayores que en un país en el que ta industria es la actividad promotora des crecimiento capiralista".(45)

Un parque industrial mayorilariamente improvisado, sin grandes muersiones fijas en la edilicia fabril propiamente dieba debió ser consecuencia de tales "contingencias y riesgos".

En ciertas ramas de la producción, fundamentales en Buenos Aires en el periodo que analizamos, la precariedad de instalaciones podría considerarse casi constifutiva. Se trata de las curtiembres y saladeros, los aserraderos y las fábricas de ladrillos.

El primer grupose liga a la actividad del maladero, cuyos antecedentes son, es sabido, un conjunto de construcciones precarias y cuy a continuacion, en los Nuevos Mataderos del Sur edificados en la decada del setenta, configura uno de los pocos ejemplos de "Proyecto" industrial en términos edilicios.

Pese a su número y a la importancia rejativa de su producción, las curtiembres se organizaban en forma muy elemental.

La: de tipo nediano constaban de "una serie de pilefas al aire libre, para bañar cuercs, un piso de piedra para el apoyo de los caballetes, y sólo un pequeño sector techado precariamente con chapa, en donde se ubicaba ia mesa de mármol para extender cueros".(46) Y no cran muy distintas las de mayor tamaño, como el caso de Jaime Roca, con "espacios abiertos con límites poco definidos que no intentan ociliar ia actividad; espacios provisorios (s.a.), que posibilitan una rápida movilidad territoriul y que al hismo tiempo evitan dejar marcas permanentes en el lerritorio".(47)

La construcción de esta "ciudad efímera" a que nos estamos refiriendo debió suponer una importancia relativa de la industria maderera mucho major que la que esta misma industria representa en la actualidad, y especialmente si a ello se suman las actividades de construcción naval y de camajes. Tampoco estas industrias requerian de instalaciones fijas importantes.

Silvestri sostiene que "los aserraderos no eran mucho más, por enfonces, que un predio recintado y algin gaipón", y extiende el empleo de estas instalaciones 
elementales a jabonerías, velerías y fábricas de aceites; $y$, al menos para el área sur de la ciudad, estima que casi todas las industrias de este período "salvo excepciones (...) no necesitan un desarrollo técnico importante $y$, en consecuencia, tampoco instalaciones especiales; la mayoría se desarrolla en espacios semiabiertos, sin formalización especiah en precarios galpones, en bloques inespecificos".

En cuanto a los hornos de ladrillos, constituyen en cierto modo una paradoja. Sin canteras cercanas, para pasar de este estado "provisorio" a un estado en cierto modo "definitivo", la ciudad debía extraer los materiales sólidos de su propio suelo: de ladrillo, se sabe, se construyó Buenos Aires. Fabricarlos era para muchos (como Miguel Navarro Viola en el sector que estudiamos) un doble negocio: por un lado proporcionaba el material básico de las construcciones, y por otro constituía una forma rentable de nivelación de los terrenos. La paradoja consiste en que las fábricas de esos ladrillos que irían reemplazando a la "ciudad efímera", fueron simultáneamente una parte sustantiva de esa ciudad. Según Silvestri esta actividad "no produce ninguna formalización arquitectónica ya que probablemente no lubiera instalaciones más precarias y provisorias que éstas".

¿Fue determinante esta modalidad de transformación y ocupación de los terrenos, de la geografĩa preexistente, en el impulso a las construcciones de albañilería, y con ello en la reclusión y ei abandono paulatino y finalmente total de las construcciones de chapa y madera? Es indicativo el debate que protagonizaron en e! Concejo Deliberante los concejales Pellegrini y Dupont en $1887,(48)$ en un momento de "ofensiva" contra las edificaciones de madera. El segundo impulsaba la prohibición de "levantar o construir edificios y cuartos de madera dentro del perímetro formado por las calles Entre Rios, Callao, Caseros y Brasil y los Paseos Colón y de Julio, y las Avenidas Alvear y Ministro Inglés", que finalmente se acordó. Por su parte Pellegrini denunciaba ese intento como "un ataque directo al derecho privado, a la higiene, al progreso y adelanto de las ciudades civilizadas", argumentando que así se implantaría un "principio proteccionista, puesto que se restringe el derecho de una industria libre cual es, las de las construcciones de madera, atentando como es natural, contra los intereses de los comerciantes y demás operarios que se ocupan en esta clase de obras". Para defender las construcciones en madera Pellegrini debía desmantelar las concepciones que la consideraban un material menor, degradado desde un punto de vista higiénico y estético. Su argumento se apoyaba en "varias correspondencias científicas, (y en) la opinión de personas de reconocida competencia en materia de higiene, que aconsejan en Europa las construcciones de madera, ya sean para establecimienios púbiicos, hospitales, asilos, etc., o bien para habitaciones particulares"; y recuerda que "existen ciudades enteras construidas de esta materia, siendo tanto o más figienicas que aquellas que lo son de mamposteria".

Dupont respondió que el uso de la madera en inctalaciones sanitarias provisorias se debía a que "pasada la causa que motisa su instalación que siempre es originada por el desarrollo de alguna epidemia, se destruyen inmediatamente por medio del fiego, 
reduciéndose a cenizas". "Las construcciones de madera que se hacen actualmente en la Capital (concluyó), no sólo resienten la estética sino que le dan el aspecto de una aldea".

El mismo estado "provisorio" o "precario" parece haber sido frecuente en otros tipos de establecimientos industriales.(49)

Los establecimientos de Noel, por ejemplo, ubicados en sus conienzos en unas construcciones bajas urbanas, tuvieron una primera expansión mediante la construcción de oficinas de madera y chapa sobre la misma terraza del primer edificio.

Todavía en 1906 las instalaciones industriales no daban cuenta de una convincente apuesta a la continuidad. En un álbum sobre las industrias italianas en la Argentina pueden verse fábricas textiles como la de la "Sociedad Italo-Americana"; de alimentos como Maletti, Loretti, Bassi (Godet), Genoud-Benvenutto-Martelli; químicas como Colonelli; metalúrgica como Merlini; edificadas en su mayor parte del modo que hemos indicado.

También los primeros frigoríficos se constnuyeron de manera provisoria, como es el caso del Swift o el de La Negra en el que todavía en 1923 se utilizaban las primitivas instalaciones de madera y chapa.

Como los galpones para espectáculos a que bemos aludido, son también barracas multiuso las que parecen haber constituido las primeras formas de las instalaciones industriales. "En la calle Belgrano 452 existe una fábrica de licores. (...) El mismo establecimiento es corralón, caballeriza y casa de inquilinato", $(50)$ señala la crónica a comienzos de la década del setenta.

En la década del ochenta, estos galpones se localizan no sólo en el sur sino también en zonas centrales de la ciudad mezclándose con viviendas e instalaciones comerciales "consolidadas". Puede verse esta caótica superposición en zonas "lejanas" como el actual barrio Norte, pero también a la vuelta de la Plaza de Mayo, sobre la calle San Martín, y por supuesto esta es la característica principal en zonas como los alrededores de la Plaza de Miserere, y en los barrios populares en formación.

Es importante distinguir entre este lipo de instalaciones, construidas en forma precaria para evitar fijar importantes inversiones, de los casos en que la precariedad es consecuencia de otros factores, como la necesidad de actuar en el menor tiempo posible. A esta última característica responden las cabinas prefabricadas utilizadas en la expansión del sistema telegráfico por todo el territorio nacional, aunque en la propia ciudad van siendo paulatinamente descartadas, como ocurre cuando la Sociedad Cooperativa Telefónica propone ubicarlas en Plaza Once y Plaza Miserere.(51) Construcciones prefabricadas provisorias fueron empleadas en el puerto de Buenos Aires, integrando un sistema de repetición.

También como parte de un sistema de repetición fueron pensadas y edificadas las estaciones y paradores de los primeros ferrocarriles, y sobre todo en la línea del Oeste.

Para un europeo como William Hadfield, sólo la condición "americana" permitía explicar la ausencia de "decoro", de voluntad estética, en una estación terminal de 
importancia. Hadfield no describe las barracas del Parque precisamente porque a fines de la década del sesenta ni siquera las juzga importantes, como sí lo era la cabecera del Ferrocarril Central en Rosario. "El principal objeto de mi visita aquí (escribe) era por supuesto ver el Ferrocarril CentralArgentino, y ciertamente, habituado a la imponente apariencia de las estaciones de trenes en Inglaterra, me impresionó fuertemente la tosquedad y el primitivismo (ready wildness) de la escena que se presentaba aquí. Unos galpones de madera dispersos en un terreno abierto, bordeado por un lado por el rio, algunos vagones de carga y de pasajeros en los rieles, constituian la terminal de una linea que se extiende 158 millas en el interior; pero todo esto era una instalación provisoria (temporary) y dará lugar a una estación permanente, actualmente en construcción...".(52)

Aún veinte años después, cuando inicia su viaje hacia la cordillera, en 1890, Child (53) también se sorprende ante la precariedad de las instalaciones porteñas de la estación terminal del Ferrocarril del Pacífico, una línea que unía los dos océanos ("un edificio de madera sin pretensión alguna"). Como en otros aspectos de la vida de la ciudad, el viajero francés interpreta esto como una actitud de cierta negligencia estética, "a la americana", muy similar a la que ha conocido en el norte del continente.

Se seguía sin duda todavía el principio de Sarmiento. Si la primera estación del Parque fue un modesto barracón de madera, también lo fueron luego las dos versiones de la estación de Plaza Once y muchas de las estaciones menores. E igualmente precarias fueron hasta los comienzos del siglo XX (y en el caso del Ferrocarril San Martin continúan siéndolo), las instalaciones de las estaciones terminales de Retiro.

Frente mismo a la Casa Rosada, la Estación Central era una construcción prefabricada en madera y chapa que se incendió en los últimos años del siglo. La transformación de las opiniones sobre este edificio muestra las modificaciones operadas en la mentalidad sobre el valor y el concepto de lo precario. En el ' 87 se celebró su incendio por baber librado a la ciudad de un espécimen edilicio excecrable, mientras que dieciséis años antes, en el 71, se había festejado la entrada a puerto del "Ticho Brabe", el navío en que llegaba "el edificio (que) será aun más espléndido que la Estación del Parque".

Del lado sur de la misma casa de gobierno se encontraban como ya hemos visto, las instalaciones de la estación Venezuela y las de los tranvías que de allí partían.

VI.

Si bien es cierto que detectamos a la "ciudad etimera" tranada con las de las ciudades sólidas (los restos de la vieja aldea, los a tisbos de la metrópolis moderna), su presencia es suficientemente importante como para permitirnos comprender que fue este ambiente mayoritariamente "provisorio", el que configuró el marco urbano que debió habitar la "generación del ' 80 " mientras soñaba y estaba construyendo la ciudad del Centenario. Quizás por esa ley de dislepsia entre los fenómenos económico-políticos y los culturales, la "ciudad de la oligarquía" parece más bien un producto del siglo XX, un resultado 
póstumo si se quiere, por cuanto su esplendor se alcanzará luego de 1914, la fecha considerada por muchos como el momento de inflexión del modelo originario.

Sumidos en una realidad estructural inadecuada a la expansión de la población y sus necesidades a comienzos del período, y en un gigantesco obrador en los tramos restantes, los porteños de las últimas décadas del siglo XIX parecen taber vivido más “cerca del Misissipi" y en un ámbito mucho más desestructurado de lo que las representaciones posteriores ban transmitido. Quizás Buenos Aires quería llegara ser la París del Sur, pero sus barones Haussmann no contaban con las maravillosas piedras del barroco y el medioevo, y debieron atravesar en cambio unos andurriales de barro y paja, de lata y madera. Tanto desdén por el yanqui "sin gusto" en la retórica de buena parte de la élite (en Cané como paradigma), señala quizás con la forma del deseo esta cercanía de lo real.

El relevamiento de este pandemonium sugiere muchas preguntas cuyas respuestas se sitúan fuera de este tipo de estudios.

Algunas refieren a la permanente "emergencia" que parece caracterizar las condiciones de vida de los más pobres; otras a las ficciones que construyen la cultura de la élite. En referencia al paradigma urbano que en esa "ciudad" se cela, las respuestas afectan a la ciudad contemporánea, en la medida en que los urbanistas ban trabajado tradicionalmente hipótesis de recomposición de una armonía, que de acuerdo a las representaciones históricas alguna vez habría sido propia de Buenos Aires. De confirmarse las hipótesis de Aliata sobre la compleja estructura urbana de la primera mitad del siglo XIX y las aquí presentadas en relación a la segunda, se refutaría esa representación, y en consecuencia se haría necesario repensar el actual océano metropolitano no como una patología sino sólo como la expresión presente de una historia general de la inestabilidad y el "desorden".

\section{NOTAS}

(1) Eatiendo por "representaciones de la ciudad" a las imágenes que consiruimos de ella sobre la base de los lestimonios con que conlamos pasa un periodo delerminado. Como lo reconoce Bachelard, las reconstrucciones de los aconiecimientos históricos en tanto manifestaciones de la memoria, no pueden eludir ser imaginadas en un espacio y según unas formas determinadas. Son este espacio y estas formas en sentido amplio lo que aquí uesignamos como "representaciones".

(2) A la formación de estasrepresentaciones han contribuido los trabajos publicados hasta ahora sobre la historia de la arquitectura de Buenos Aires durante el período. Un ejemplo es la nola 14 del capítulo 4 del "Buenos Aires" de James Scobie, donde se citan como "refercncias útiles": BUSCHLAZZO, M., La drquitectura en la República Argentina, 1810-1930, Buenos Ajres, 1966; GAZZANEO, J. y ESCARONE, M., Arquitectura de la revolución industrial, Buenos Aires, 1966; 1AA/FADU/UBA, La arquitectura de Buenos Aires 1850-1880, Buenos Aires. 1965; MARTINI, J. y PENA, J.M., La ornamentación ent la arquitectura de Buenos Aires, 2 volúmenes, Buenos Aires, 1966-67; ORTIZ, F. elal.,La arquitecura del hiberalismo en la Argenina, Buenos Aires, 1968; a los que se agrega, MORALES, C., "Estudio Topográfico y edilicio de la ciudad de Buenos Aires", en Censo Generai de la Ciudad de Buenos Aires, Buenos Aires, 1909.

(3) Cfr. ROCCHI, F. y JOHNS, M., Capitalindustrial y espacio urbano: Buenos Aires durante el auge del proceso agroexportador, Ponencia presentada en las jornadas "Buenos Aires Moderna. Historia y perspectiva urbana (1870-1948)". Instituto de Arte Americano e Investigaciones Estéticas "Mario 3. Buschiazzo", Buenos Aires, mayo de 1990 . 
(4) Son casi imperceptibles las oscilaciones de significado entre precario, efimeto, transitorio, provisorio, fugaz; y el diccionario no aporta demasiadas precisiones: llama efimero a aquello "que dura un sólo dia" o es "pasajero, de corta duracion, provisorio"; fugaz a 10 "que desaparece en seguida"; transilorio a to "pasajero, que no dura, momentáneo"; provisional a lo "dispuesto interinamente"; pasajero a lo "que pasa pronto"; precario a algo "que depende de otro. De poca esiabilidad o duración; incierto, inseguro; que existe en virtud de una tolerancia que puede cesar". Con extos adjetivos puedeñ desigaarse desde construcciones prefabricadas de larga vida átil hasia aquelias que fueron realizadas con materiales de desecho por carecerse de otras posibilidades.

(5) Negativo B.118,622, Archivo Gráfico de la Nación. Buena parie de las ideas que aquí se presentan se fueron produciendo y confirmando ea la observación de una innumerable cantidad de imágenes fotográticas que lestimonian la existencia de esta "eiudad efimeta". Cruzando esta información con otro tipo de documentos más "tradicionales" (censos, relevamientos de campo, eatastros, elc.) se confirman las observaciones primeras. Extrañamente, nos negamos a dar crédito a nuestros propios ojos. Los principales álbumes consultados fueron: Centenario argentino, álbum historiográfico de ciencias, artes, industria, comercio, ganadería y agricultura, Buenos Aires, 1910-1911; El libro de Mayo. República Argentina 1910-1911. Exposición Lnternacional Argentina, Buenos Aires, 1911; Album Gráfico del Centenario, Buenos Aires, 1911; llustración Hisiórica Argentina, Buenos Aires, 1908: Buenos Aires, Fototipias Peuser, Buenos Aires, 1920; Primo Centenario della Indipendenza della Repubblica Argentima. 1810-1910; La Nación Argentina, Buenos Aires, 1916; La República Argentina en su primer Centenario, Buenos Aires, 1910: Buerios Aires de ayer y de hoy, Buenos Aires, 1921; Buenos Aires anuiguo, Buenos Aires, 1925; TAULLARD, A., Nuesiro artiguo Buenos Aires: cómo era y cómo es desde la época colonial hasta la actualidad, Buenos Aires, 1927; Comitato delia camera italiana di commercio ed alır, Gli izaliani nella Repubblica Argentina, $1905 ;$ A lbum devisias del Ferracarril de la Provincia de Buenos Aires, Buenos Aires, 1889; Album de vistas y costumbres de Buenas Aires, Buenos Aires, 1883. A estas imágenes deben agregarse las de los magazines, PBT, Caras y Caretas, El Sudamericano, además de las folografias del Archivo Gráfico Nacional y del Archivo Grático del Instituto de Arte Americanoe Investigaciones Estéticas "Mario 1. Buschiazzo" vinculadas a los temas aquí tratados.

(6) SCOBIE, J., Buenos Aires. Del Centro a los barrios, Bs. As., 1977.

(7) Cfr. para Anérica Latiaa: el trabajo (inédito) de Pedro Romero acerca de los campamentos petroleros en Maracaibo; GOMEZ DA SILVA, G., Arquiturara do ferro no Brasil, Sao Paulo, 1986; GUARDA, G., Provincia de Osorno. Arquitiectura en madera (18.59-1928), Santiago de Chile, 1981; GARCES, E., Las ciudades del Salitre, Santiago de Chile, 1988: en 26 corstrucción de la ciudad, N 19, Barceiona, 1981, han publicado distinlos trabajos sobre poblados industriales Ramón Gutiérrez, Marla Silva, Graciela Viñuales, Olga Paterlini, Rosa Guaycochea, Marina Taran. Atberto Nicolini y María Ester Leiva.

(8) El Nacional, Buenos Aires, 27/01/1871 y 17/03/1871.

(9) HADFTEL D, W., Brasil and the River Plate in 1368. Showing the progress of those countriss since his former visit in 1853, London, $186 \%$.

(10) CHuLD, T., A travers !'Amerique du Sud, París, 1891.

(11) Presenta también un proyecio el ingeniero Casimir Chanoine, Archivo Histórico Municipal de la Ciudad de Buenos Aires (en adelante AIMCBA), Legajo (en adelante L) 2, Obras Públicas (en adelante OOPP), Carpetz (en adelarte C) 960 . El proyecto de Abeio se encuentra en A.HMCBA, L2, OOPP, C969.

(12) El Nacional, Buenos Aires, 30/03/1871.

(13) Archivo General de la Nación (en adelante AGN), L36, Expediente (en adelanle E) 6031, Ministerio del Interior (en adelaute MI).

(14) También presentó una oferta, de un bartio con paredes de màdera de pino y iecho de chapas, la empresa Ramos Capurro y Companíía, AGN, E6070, L36, MI, 18/12/1886. Ctr. la oferta de Sackman y Ocampo en AGN, E6148, L36, MI, 20/12/1886.

(15) Cfr. BIL IK, M., El hotel de inmigrantes inédito.

(16) AHMCBA, L2, OOPP, C3311, 21/12/1876.

(17) ESTRADA, S. Viajes y oiras páginas iterarias, Buenos Aires, 1889, citado ea PAEZ, J., El Contvensillo, Buenos Aires, 1970

(18) En 1883 Juan Francisco Castaing pidíb perniso para "construt piezas de madera en la azolea con arreglo a lo que mejor se constrivye en la capiial" en Piedad y Artes con el objeto de ampliar el Almactén del Molino, en AHMCBA, L10, OOPP, C5528, 22/,1/1883. 
(19) AHMCBA, L18, OOPP, C9370, 16/08/1887.

(20) Cuando se alerta sobre una situación peligrosa en la calle Alsina 802 sl inspector observa que "existe efectivamente un galpón de madera con dos piezas agregadas al fonlo de altos también de madera (...). Por lo que respecta a su mal estado, (...) no hay tal peligro, siendo una prueba de ello el fiaber resistido a los temporales últimos sin hacer el minimo movimiento". En AHMC BA, L18, OOPP. C11593,30/09/1897. Podemos inferir que con cierta frecuencia los vientos hacian estragos. Otro deouncianle dice haber "visto descargar maderas usadas en el ter eno que hoy ocupa Don Antonio Astincio. Ahora veo que se arma una casilla de tabias, y camo desconozco el contrato...".

(21) HURET, J., De Buenos Aires al Gran Chaco, Buenos Aires, 1988 (primera edición francesa, París, 1911). (22) PASCARELIA, L, El Conventillo, Buenos Aires, 1918, citado en PAEZ, J., op. cit.

(23) Conferencia de las Serioras de la Sociedad San Vicente de Paul en la Repuiblica Argentina, Buenos Aires, 1914.

(24) CHILD, Th., op. cit.

(25) FRAY MOCHO (José S. Alvarez), "Memorias de un vigilante", en Obras Completas, Buenos Aires, 1954.

(26) Algunos debieron ser el café Chavari, en la esquina de Cuyo y Uruguay y el café lália, freate al mercado del Plata.

(27) GUTIERREZ, L y GONZALEZ, R., "Pobreza marginal en Buenos Aires, 1880-1910", en AA. VV., Sectores populares y vida urbana, Buenos Aires, 1984.

(28) Caras y Caretas se refiere al "loco de la barranca", habitante de una gruta.

(29) FRAY MOCHO, op. cit.

(30) PBT, Buenos Aires, 26/01/1901.

(31) Caras y Caretas, Buenos Aires, 08/06/1901.

(32) HURET, J., op. cit. Cfr. para Rosario, ARMUS, D., y liARDOY, J., "Conventillos, ranchos y casa propia en el mundo urbano del novecientos", en ARMUS, D. (comp.), Mundo urbano y Culsura Popular, Buenos Aires, 1990.

(33) Cfr. URQUUO, H., Tipos predominantes de vivienda natural en la Repriblica Argentina, Buenos Aires, 1969; VIÑUALES, G., "Introdueción a los usos del adobe en la Repúbica Argentina", en Ariales del Irstisuto deArle Americano, $N^{\circ} 27$, en prensa.

(34) Existe abundante bibilogratía y buena parte del barrio sobrevive hasta nuestros dias, de manera que no parece necesario abundar aquí sobre el tema.

(35) GUEVARA, C., "La Boca, su historia urbana y su composición éınica", en Aula les del lnstituto de Arte Americano, N2 26, Buenos Aires, 1988.

(36) En un trabajo sobre la situación sanitaria en otra zona del país se corrobora que "como en casi todas nuestras ciudades (s.a.), la natioraleza del terreno sobre el cual se levanta la ciudad de Saltu ha sido alterada en sw compasición (...) por los desperdicios de todo género que bajo forma de basuras arrojadas en el fondo mismo de las casas, servian para levantar las partes bajas del terreno o rellenar los pazos que allí mismo se cxcavaban cont el fin de extraer tierra para la confección de materiales, adobe, con los que debia construirse el edificio". "Censo sanitario de las habitaciones de la ciudad de Salta", La Semanta Médica, 14/02/1901.

(37) Famatina 3570, Famatina 3505-07, Famatina 3511-13.

(38) Famatina 3511 y 3545 .

(39) Censo General de la Ciudad de Buenos Aires, 1904.

(40) Una localización posible sería la parte norte de las tierras que perienecian a la familia Navarro Viola (Tupungato-Aluel-Aconcagua-Pepirí).

(41) "Cuando aiguien no aguanta más al vecino de enfrente, o le molesta el paso de los irenes, o le resulta insoportable el olor de la curtiembre cerculu, o seitcillamente quiere agregar otra habitación y le falia espacio, ahorra unos pessos, adquiere el terreno que le pormitu realizar sis deseos, y se muda. Con casa y todo. Parallevar a cabo ese trabajo está Rosendo. La operación es simple Primero, desatornillarla de los pilares que la sostienen y despejar el camino quitando alambrados y otros obstáculos. Utiliza como rodillas tres largos troncos, los coloca debajo de la casa, conecta un grueso cable de a cero y su caballo se encarga de movilizarla; cuando el úlimo rodillo queda afuera lo pasa adelante". GOMEZ BAS, J., Suburbio, Buenos Aires, 1982.

(42) Guillermo Donte protesta contra la Oficina de Obras Públicas que lo intinaba a retirarsu casilla por ocupar la calle, "en esto tienc que haber error-argumenta-, yo señor tengo mi fítulo de propiedad que daia de enero 12 
de 1850, en 1881 cuando hice la casilla que se pretende hacer levantar". AHMCBA, L3, OOPP, C7382, 26/ $11 / 81$.

(43) Los vecinos de San Juan Evangelista piden que se obligue a José Ratto "a colocar en la linea cor respondiente la casilla de su propiedad (...) que se encuenura obstriyyendo la vía pública", AHMCBA, L3, OOPP, C3196, $30 / 09 / 78$.

(44) Jusa Bagle pidió "permiso para trasiadar una casilla de mi propiedad situuda en la calle 202 sección 20 a la calle Rocha entre las culles 129 y 130", AHMCBA, L.18, OOPP, C8722, 09/08/87. En ol caso de Angelo Gaitano se le concedió autorización "sienpre quela haga en les horas matinales", AHMCBA, idem Bagle. AJgo similar ocurtió a Nicolás Dogliania a condición de hacerio "a horas que no interrumpa el tráfico público", AHMCBA, 1.10, OOPP, C5267,16/11/33.

(45) SABATO, J, La clase dominante en la Argentina modersta. Formación y caracieristicas, Buenos Aires, 1988.

(46) Cfr. SILVESTRI, G., La fábrica, el río, la ciudad: la constitución del eje industrial metropolitano en el períado 1870-1930, Informe CONICET, Buenos Aires, 1991.

(47) lbídem.

(48) Actas del Concejo Deliberante, 1887.

(49) "La mancanza di uno stabile indirizzo nella politica economica spaventa il capitale. Gli impianti sono timidi, si incomincia dal poco", confirma el relator de Gli Italiani nella República Argentina, publicado por el Comitato della Camera Llaliana di Commercio ed Arre, 1906.

(50) El Nacional, Buenos Aires, 10/03/1871.

(51) Se ilustran estas casillas en Caras y Caretas, 16/06/1901.

(52) CHIL, Th., op. cit.

(53) Idem. 